\title{
Research Prospect of General Ammunition Maintenance Planning Decision
}

\author{
Qi Wang, Xihui Mu, Xiaoming Lv \\ Shijiazhuang New Technology Application Institute, Shijiazhuang,050003, China
}

Keywords:general ammunition,maintenance planningdecision,index system,optimization model.

\begin{abstract}
Aiming at the urgent issues of our military ammunition maintenance decision, the necessity of developing general ammunition maintenance decisions is explained; the current defects of general ammunition maintenance and support are focused on the basic idea that carrying out the work of general ammunition maintenance decisions in the next stage is proposed.
\end{abstract}

\section{Introduction}

For a long time, army has paid insufficient attention to maintenance work on ammunition. Since "Tenth Five-Year Plan",a lot of information technology ammunition has been equipping the troops rapidly, such as rocket series, artillery missiles series,etc. Most of them have characteristics of single high-value and less strategic reserve. During "Twelfth Five-Year Plan" period, the information technology ammunition is about to reached ammunition factory warranty period, which has no clear criteria to be used, maintained for life extension or scrapped[1]. The urgency of maintenance decision further illustrates that our military ammunition maintenance work can not be overlooked, and studying all kinds of our military general ammunition maintenance decision must be enhanced based on the information ammunition maintenance decision task as an opportunity.

In ammunition maintenance activities, the maintenance plan [2] has a commanding role. Itmainly arranges and normalizes contents,procedures and executing methods of ammunition maintenance work scientifically to solve the basic problem "repair or not, repair how much,when to repair"on ammunition to be repaired. Scientific and reasonable maintenance plans can reasonably arrange the task size and timing under conditions of maintenance capacity and resources allowing, and can achieve the best balance in ammunition production, use, maintenance and retirement to achieve a reasonable resource configuration accessing to the largest military and economic benefits.Therefore,how to analyse the index system of maintenance,life extension and scrapping, and how to make scientific and rational maintenance planning decisions on the basis of considering reserve requirement, maintenance capabilities and maintenance benefit-costratio become the most important issue to be solved.

\section{The necessity to carry out general ammunition maintenance planning decision}

The necessity to carry out general ammunition maintenance planning decisions, mainly reflection the following three aspects:

\subsection{The traditional method of maintenance decision is not enough scientific}

Currently, the military ammunition maintenance decision is mainly based on experience, whose reason is "ammunition quality grading standard" that is new, worthy of supplies, materials for repairs,and waste.Take product to be repaired as maintenance decision objects.There are less decision indexes and quantitative analysis lacking of unified scientific methods in the decision-making process [3].The traditional concepts and methods of maintenance decision can barely meet the maintenance needs of traditional ammunition, but the problems of excessive resources consumption, unscientific spending and environmental pollution have been exposed.Especially for the less reserve,single high-value information technology ammunition, it is more difficult to apply, and badly in need to develop an actual decision process and method to provide scientific guidance for maintenance decision. 


\subsection{The contradiction between maintenance needs and resources}

With the various types of information technology ammunition entering into repair period in bulk, maintenance pressure is increasing. Repairing it back to tactical and technical performance as soon as possible to meet the needs of military training and readiness reserve, has become an important issue of ammunition supportcurrently.But maintenance capability at all levels of our military ammunition maintenance institutions is generally inadequate: although the headquarter ammunition maintenance factories has built repair lines of some kinds of the information technology ammunition, butcan not cover the whole kinds and the whole process; maintenance facilities and equipment of military region ammunition repair stations and grassroots ammunition depots are in inadequate conditions.Therefore, a scientific and rational plan of ammunition maintenance work need to be made, so that maintenance tasks and processes can be more closely orderly and achieve mating orderly between maintenance requirements and maintenance resources.

\subsection{The complexity of maintenance decision work.}

Characteristics of "long-term storage, once only use" and technical features of integrated multidisciplinary field of knowledge make maintenance decision to become a complex system engineering.Especially information technology ammunitionwith a lot of new principles, new technologies, new materials and new craft increasing the proportion in general ammunition, make more diverse, complex, and bring a great deal of difficulties and challenges to maintenance decision work [4]. Hence, it is urgent need for its in-depth special study of ammunition maintenance decision theory to guide our military ammunition maintenance and support developing timely and orderly.

\section{The problems of military general ammunition maintenance and support at this stage}

Overall, there arethe following outstanding issues about military generalammunition maintenance and support at present.

\subsection{Comprehensive verification is not sufficient and the top-level design is less scientific}

There are many types of military general ammunition whose year of production across a large range with different support characteristics guarantee. The support work of ammunition maintenance is complex. However, the current military ammunition storage and maintenance units at all levels lack of carding quality and quantity of ammunition status, storage life and technical indicators systematically, and lack of analyzing and forecasting the status quo of ammunition maintenance and support need scientifically, which lead to the guidance of engineering research and capacity construction not enough. Military readiness, maintenance benefit-cost ratio relationship, ammunition technical features, support capabilities and other factor shave not been considered synthetically during the period of maintenance planning, tasks division, model reform and resource allocation.Lacking of ammunition life-cycle management thinking results in the resources and funding wasting, and the impact of troops fight and training.

\subsection{Sectional coordination is not close and system construction is not perfect.}

While each department of maintenance decision, quality inspection, maintenance and others has formed a certain extent transmitting in information management, less collaborative between planning and decision-making departments and others.They grasp the demand of the ammunition technical condition, ammunition consumption and ammunition readiness so inaccurately leading to insufficient scientific planning and operabilitynot strong. Such as the division of tasks is not clear, the task amount of each maintenance institution is uneven and so on. Ammunition maintenance and support capacity construction has not formed a complete system, leading to the presence of many loopholes in the maintenance planning management. In particular, high-tech ammunition of new materials and new technology lack of maintenance and support system covering regulations and standards, equipment tools institutional facilities, technical data, personnel training and other aspects, which make its maintenance capability weak and failure modes and mechanisms not yet clear grasped.

\subsection{Maintenance capacity construction is hysteretic and maintenance mode is single}

Military ammunition maintenance system has been established of three levels, but due to historical reasons and concepts issues, our military ammunition maintenance institution sespecially 
the grassroots-level and intermediate-level ones have been lacking of maintenance tasks supporting for a long term which results in capacity construction seriously lagging behind current development pace of new types of ammunition, such as lacking of control, high degree of automation equipment and complete testing equipment and safe good maintenance tools and equipment [5].In particular, traditional ammunition maintenance projects of rust, up painting, coating oil have been unable to meet the new ammunition maintenance needs, which lack of adaptation of new ammunition quality monitoring, fault detection, life extension methods and means. Meanwhile, the maintenance decision is too simple and rough, and do not absorb advanced technology decisions.Experience-based maintenance dominates and lack of a unified, detailed and scientific criteria, such as maintenance financial standards are too simple and hysteretic.

\section{The basic idea sof general ammunition maintenance planning decision}

Carry out ammunition maintenance planning decision work must extract the key affecting factors based on a profound analysis of military ammunition maintenance structure and system in order to build a scientific and workable decision model, optimize the model and work out the best maintenance plan.

\subsection{The analysis of general ammunition maintenance system}

Maintenance system determines the way and capacity of maintenance. Therefore, before performing maintenance planning decision, general maintenance institutions setting up, grading, task allocation, system specification and other issues must be focused on. The pros and cons of the existing process and mechanisms must be analysed in order to summarize the new ideas and new requirements meeting military ammunitions maintenance and support conditions which lay the foundation of military ammunition maintenance planning decision [6].Among them, information material mainly include: academic papers and dissertations at home and abroad, the military and national standards, regulations and technical information, force data on ammunition storage, use and maintenance, data of maintenance institutions for ammunition maintenance.

\subsection{The index system of general ammunition maintenance planning decision}

In the process of building maintenance planning decision index system, firstly collect and screen the decision indexes, and select indexes which have greater influence,such as ammunition reserve demand, maintenance benefit-cost ratio, maintenance and support capacity, and so on; get rid of the indexes which have smaller influence. Secondly, make level division of indicators corresponding impact factors into the primary indicator, the secondary indicators, and so on. For instance, the primary indicator " maintenance and support capabilities " of maintenance institutions can be divided into secondary indicators about maintenance facility and equipment, maintenance personnel, maintenance management,etc.which can be divided into three-level indicators, shown in Figure 1. Thirdly, through analytic hierarchy process calculate the weight of all levels of indexes which can quantify the importance of each index, and finally build index system of ammunition maintenance decision.

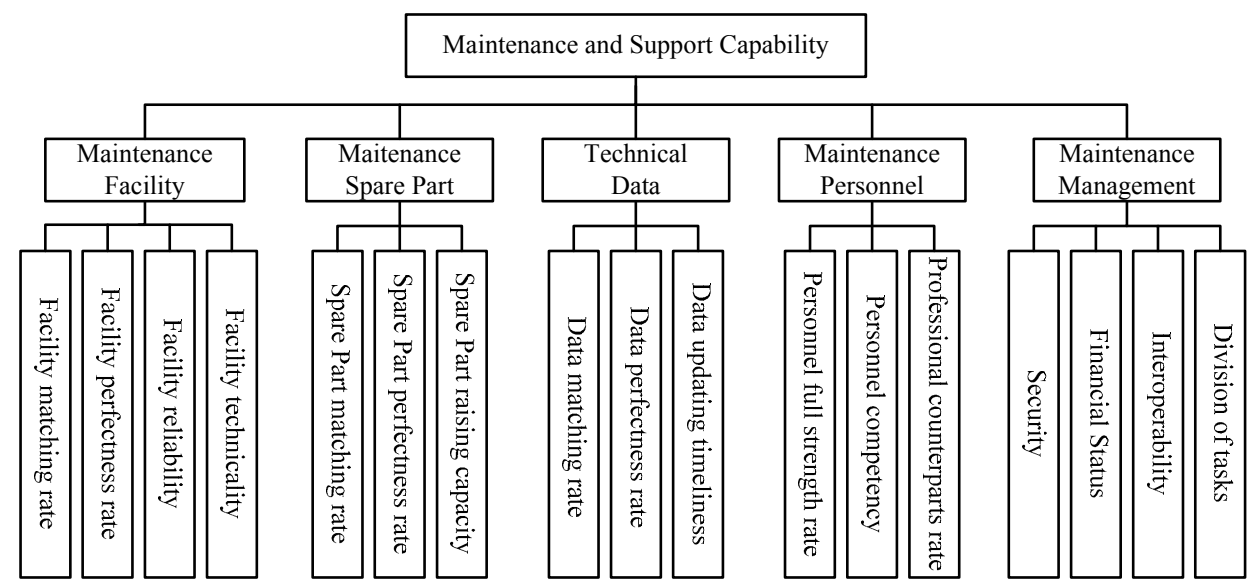

Fig.1: Index system of maintenance and support capabilities 


\subsection{The process analysis of general ammunition maintenance planning decision}

Previous maintenance planning decision process of the ammunition to be repaired is often more traditional experience, the lack of scientific standards. Therefore, on the basis of taking full account of the maintenance planning decision indexes, establish general ammunition maintenance planning decision process based on decision model, shown in Figure 2. Firstly, in the preparatory stage must understand and grasp maintenance capabilities of all levels of military maintenance institutions, reserve of various kinds of general ammunition, and so on. Secondly, establish the corresponding maintenance planning decision model according to the senior specific annual general ammunition maintenance tasks. Thirdly, according to the model in different classification module, determine the optimal targets and constraints of the maintenance planning decision to the maintenance decision factors as optimization variables. Then, select the appropriate optimization algorithm to optimize the parameters of the model, and evaluatethe optimization result. Finally, iteration, and gradually achieve the optimal solution. When the optimization results to meet mission needs,output decision results, and develop an ammunition maintenance plan.
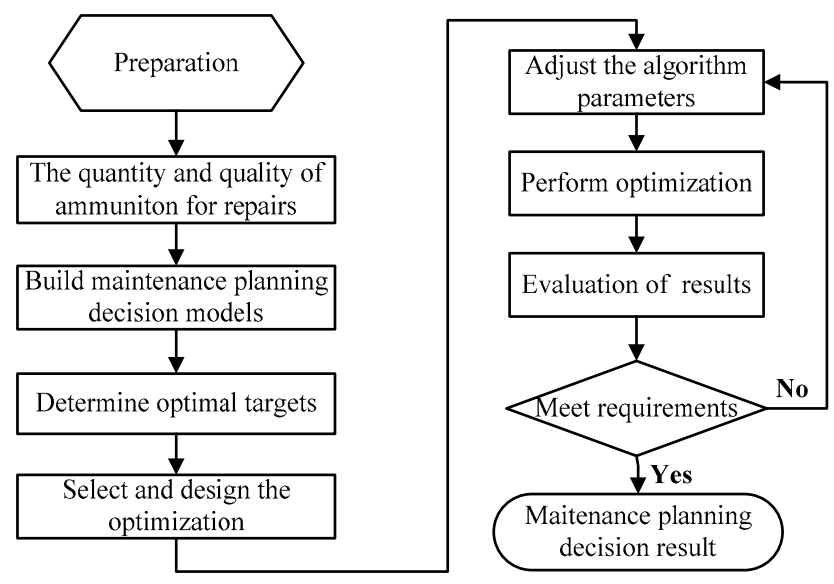

Fig.2: Process Analysis of maintenance planning decision

\subsection{Modeling and optimization of general ammunition maintenance planning decision}

Firstly, according to different mission requirements of the annual ammunition maintenance, determine different decision goals, mainly the highest availability, the highest average benefit-cost ratio, the highest reliability and so on.For example, in the year of ammunition maintenance financial constraints, "the highest average benefit-cost ratio" can be adopt; and to achieve the best performance of ammunition, the decision goal of "the highest reliability" can be adopt; and so on. Also, the above two or more goals can be adopt. Secondly, based on comprehensive consideration of the index system, establish workable general ammunition maintenance planning decision single or multi-objective model.Thirdly,optimize the decision model.Forsingle-objective decision model, that can be taken to simulated annealing and evolutionary computation to solve; for multi-objective decision model, that can use analytic hierarchy process to calculate different target weights to change multi-objective decision model into single-objective one;also can directly use genetic algorithms and neural networks to solve it.

\section{Summary}

All along, our emphasion military ammunition maintenance and support work is not enough. The realistic problem of ammunition maintenance decision tasks further illustrates the necessity and urgency of developing general.This paper proposed a basic ammunition maintenance planning decision concept of "decision index system making, decision process reengineering, decision model building and optimizing", based on analyzing the shortcomings of ammunition maintenance system and mechanism, in order to point the direction of carrying out general ammunition maintenance planning decision for the next phase. 


\section{References}

[1] Niu $\mathrm{Y} T, \mathrm{Mu} \mathrm{X} \mathrm{H}$. Research prospect of information ammunition storage life evaluation[J].Equipment Environmental Engineering, 2013,10(5): 94-101.

[2] Hao Y A, Gu Z G. General ammunition maintenance technology[M].Beijing: National Defense Industry Press, 2007,12.

[3] Zhong W J, Zhao X L, Jin R J, et al. Study on the maintenance decision of new type ammunition[J].Missile and Guidance, 2005,25(2): 365-369.

[4]Fan Z F. Development and characteristics and support countermeasures of information technology ammunition[J].Defense Technology Base, 2010(9).

[5]Ma Q S, Gong Y X, Ding Y K, et al. Ammunition maintenance and scrapping[M].Shijiazhuang: Ordnace Engineering College, 2004.

[6] Shi C M. Research on maintenance planning decision-making of Armored Vehicles[D].Changsha: National University of Defense Technology, 2010. 